\title{
O ANIMAL CORDIAL: UMA RASURA DA RAZÃO
}

\author{
Fernanda Marra
}

\begin{abstract}
RESUMO
Este artigo propõe uma leitura do filme longa metragem $O$ animal cordial (2018), da roteirista e diretora Gabriela Amaral Almeida. A ideia foi percorrer o enredo contemplando as personagens e descrevendo como a roteirista e diretora brasileira colocou em cheque a validez e a pertinência da noção de "homem cordial", descrita por Sérgio Buarque de Holanda (1995) em sua obra sociológica Raízes do Brasil. A proposta é observar (1) como esse significante persiste na contemporaneidade a despeito de seus envios anacrônicos e (2) de que forma o filme é, para além de uma leitura de homenagem ou denúncia desse anacronismo, uma possibilidade de reescrita do conceito pela sua rasura. Almeida filma uma noite em um restaurante brasileiro frequentado por pessoas pertencentes a uma classe social média-alta, ou economicamente ascendente. Nessa noite, o que se assiste é ao processo de ruína do "homem" que dá lugar ao "animal" e promove, com isso, uma sobrescrita não apenas do homem como do humano. É essa reescrita violenta e manchada de sangue o que me interessa no filme. É isso o que apresento neste texto amparada pelo pensamento de Hélène Cixous (1995), Alexandre Nodari (2017) e Achille Mbembe (2018), pois, a meu ver, é esse processo que o longa brasileiro expõe tão linda e visceralmente encetando devires.
\end{abstract}

\section{Palavras-chave}

Animal cordial; homem cordial; cinema brasileiro; alteridade; devires

\section{O ANIMAL CORDIAL: AN ERASURE ON REASON}

\begin{abstract}
This essay proposes a reading about the fill-lenth film $O$ animal cordial, of the screenwritter and director Gabriela Amaral Almeida (2018). The ideia was to cover the plot observing the characters and describing how the Brazilian sreen-writter and diretor questioned the validity and the appropriateness of the expression "homem cordial", described by Sérgio Buarque de Holanda (1995) in his sociological analysis found in the book Raízes do Brasil. My proposal is to perceive (1) how that significant persists in contemporaneity in spite of its anachronistic sendings, and (2) in which way the film, beyond being a complaint-reading of this anachronism, is also a possibility of a rewriting of the concept by obliteration. Almeida (2018) films a night in a Brazilian restaurant attended by people who belong to an upper-middle social class, or to a class that moves economically upward way. What we watch that night is the downfall process of the "man" who changes place with the "animal" and brings about an overwriting, not only of the "man", meaning the masculine genre, but of the "humankind" as a hole. This violent and bloody rewritting is what interests me in this film. In other words, what I present in this text stood up for the thinking of Hélène Cixous (1995), Alexandre Nodari (2017) and Achille Mbembe (2018), because, to my point, this process is what the full-lengh Brazilian film exposes in a beautiful and fierce way pointing "devires".
\end{abstract}

\section{KEYWORDS}

Animal cordial; homem cordial; Brazilian film; otherness; "devires" 
O presente artigo contempla o filme longa metragem $O$ animal cordial, de Gabriela Amaral Almeida (2018) a partir de uma leitura realizada sob o impacto da fruição da obra e de leituras recentes que realizei no âmbito da filosofia, sociologia, antropologia e psicanálise. Ressalto que o intento foi apresentar a perspectiva pela qual o roteiro e as imagens dessa obra cinematográfica ganharam sentidos particulares à medida que assistia ao filme. Assim, diria que o viés pelo qual o filme é abordado nesta leitura parte da escolha do título conferido à obra e da remissão ao conceito proposto por Sérgio Buarque de Holanda (1995). A identificação da referência ao historiador que pesquisou e teorizou sobre o período colonial brasileiro nesta proposta de leitura, contudo, não se limita em homenageá-lo passando em revista simplesmente seu conceito. A complexidade da obra de Almeida (2018) está, tal como espero demonstrar neste artigo, em discutir a partir de uma estética cinematográfica o processo pelo qual a expressão "homem cordial", apresentada como uma redução que explica e funda certa ética brasileira, está ancorado no desgaste, na rasura e no esvaziamento conceitual desse termo. O desembaraço com que o título remete ao conceito de Holanda (1995) seria um indício de que a noção da cordialidade sugerida pelo historiador não está superada. No entanto, o que a cineasta propõe com a obra fílmica é um ultrapassamento, uma atualização do significante que tem lugar entre a homenagem e a denúncia. Ao trazer a expressão para o título do filme, Almeida (2018) não resgatou a noção de cordialidade fazendo com que servisse às personagens contemporâneas como uma roupa desusada. Contudo, promove por meio da narrativa cinematográfica uma descida do humano ao animal, ao que resta de genuinamente pulsional nos cidadãos ditos civilizados para justapor e ressignificar a noção histórica de cordialidade. Logo, é por causa desse processo da corrosão, que não só põe em questão uma ética consagrada por uma tese historiográfica como reescreve e reenvia essa nomeação ampliando o espectro de possibilidades que tal expressão possa significar, que este texto aborda essa obra.

O filme longa metragem, O animal cordial, é ambientado nas dependências de um restaurante de classe média alta, situado em região de vida noturna erma de uma grande cidade brasileira. Sabemos disso pelo fato de o filme começar com o final de expediente em que os funcionários do restaurante se preocupam com o horário de sair em razão do funcionamento do transporte público e são instados pelo patrão, Inácio (Murilo Benício), a permanecerem no estabelecimento. Inácio quer que os funcionários permaneçam e atendam os clientes que chegam para jantar faltando poucos minutos para o horário de encerramento da jornada. Fica evidenciada a tensão pela situação que se insinua corriqueira.

Um clima hostil entre patrão e empregados vai se desenhando nos diálogos e na composição do ambiente claustrofóbico do restaurante. Djair (Irandhir Santos) comanda a cozinha com o auxílio de dois ajudantes. No salão, a garçonete e braço direito do patrão, Sara (Luciana Paes), divide com ele o espaço do balcão. Nas mesas, um homem solitário (Ernani Moraes, como Amadeo) aguarda seu prato. O casal, Verônica (Camila Morgado) e Bruno (Jiddu Pinheiro), aporta no restaurante demorando-se a decidir pelo que comer e esbanjando conhecimento e arrogância no pedido do vinho. Sara conversa com um dos funcionários, Lúcio (Diego Avelino), com quem fica evidente uma relação 
de intimidade em um ambiente privado. Ela está exausta, clama de dores no corpo, ele a convida para sair, mas, com a chegada dos novos clientes, o patrão vem pedir ajuda e ela se oferece para atendê-los, deixando que Lúcio vá embora.

Os auxiliares da cozinha, porém, deixam o restaurante irritados e passam pelo salão largando o lixo, que não conseguem levar para fora do estabelecimento porque a porta está sempre trancada. Essa atitude desaforada dos funcionários aumenta um pouco mais a ira do patrão que, por um acúmulo de fatores, está prestes a explodir. 0 sujeito de cabelo seboso e humor irritadiço luta para se manter no controle, mas está fracassando a olhos vistos. A invasão do restaurante por dois assaltantes (Humberto Carrão e Ariclenes Barroso), que sucede à saída dos funcionários com Sara levando o lixo para fora e sendo rendida na porta, é o acontecimento que faz eclodir a ira do empresário e leva a situação ao colapso.

\section{O HOMEM CORDIAL}

Sérgio Buarque de Holanda, em Raízes do Brasil, dedica um capítulo ao conceito de homem cordial. Holanda empreende um esforço interpretativo do Brasil colonial e da origem da família patriarcal que constituiria a sociedade brasileira e estruturaria as relações no âmbito da sociedade. Para o historiador, a adjetivação que buscou no radical latino "cordis" (cordas - coração) para ler o homem colonial do Brasil refere-se a uma cordialidade de superfície. De acordo com a tese, a cordialidade brasileira, a bem da verdade, não passaria de um ardil encenado no âmbito do comportamento por um homem que não suporta o peso da impessoalidade das instâncias burocráticas e que não separa o público do privado. Esse homem cordial, cuja origem remonta o período colonial do Brasil, estende a constituição da estrutura familiar calcada na figura autoritária, centralizadora e desbravadora do pai a outras esferas públicas de relacionamento, a exemplo das relações de trabalho. A cordialidade emerge da mixórdia entre os âmbitos público e privado sendo indiscriminadamente constrangidos pela figura onipotente e onipresente do pai. O pai é esse homem colonial que tem diante de si um mundo a conquistar e construir; que tudo sabe e tudo pode porque está imbuído da missão de desbravar e civilizar o mundo bárbaro e hostil. Como paladino da lógica falo-eurocêntrica do mundo, o pai, com sua lei, quer o melhor para os seus, de quem não espera menos que obediência, reconhecimento e gratidão.

Ler a crise do homem cordial a partir da personagem de Murilo Benício implica tomar a trama do filme de Almeida (2018) como uma fabulação e observar as personagens pelo funcionamento de estruturas a que dão corpo. Trata-se de uma perspectiva que permite questionar um estereótipo convidando a ir adiante com a leitura do título que, ao invés de ratificá-lo, promove uma rasura e, escrevendo por cima do conceito, retifica-o. O título faz com que os rótulos compareçam à cena para melhor desmontá-los - ou melhor, esquartejá-los - sem a ilusão de que vão simplesmente desaparecer. O fato de sinalizar com devires não faz com que o filme prescinda de um longo e mal-cheiroso processo de morte e decomposição; pelo contrário, é isso mesmo o que se dedica a exibir. 
Assim, retomo com o homem cordial, o patrão Inácio, em crise e à beira de um ataque de nervos que lhe é propiciado pela invasão do restaurante. Esse homem que não é nem tolerado, nem respeitado pelos funcionários; que é humilhado pelos clientes esnobes; que discute com a esposa ao telefone; que quebra a saboneteira do banheiro e diz para a mulher que não está nervoso porque até sorri e, aliás, não faz senão sorrir para ela, para os clientes, para todo mundo, esse homem já não sustenta a máscara puída da cordialidade e não se conforma com o fato de assistir ao seu poder se esvaindo. Seu ódio vem de perceber que o fato de ser o patrão não lhe assegura mais a manutenção do poder.

No Brasil, habituou-se chamar de "gourmetização" a tendência do mercado de criar demanda por produtos e serviços que sejam reconhecidos pela alta qualidade. $O$ rótulo de produto "gourmet", que muitas vezes compõe mesmo a estampa dos rótulos, forja uma superioridade que acaba por justificar o custo superfaturado desses produtos e serviços, cuja possibilidade de acesso faz de seus consumidores uma estirpe de pessoas distintas pelo fato de reconhecerem e terem acesso ao que há de melhor. Logo, dentro dessa lógica de consumo "gourmet", já não seria possível para o dono de um restaurante, cujos clientes integram essa casta que reivindica para si nada menos que "o melhor", fiar-se no engodo de entender mais ou menos de vinho e de comida. Sendo ele o dono de um restaurante que se dispõe a atender uma elite emergente viajada, informada e pretensamente refinada e que busca se destacar esbanjando tudo isso como trunfos de sua ascensão econômica e social, seria preciso se profissionalizar e valorizar um pouco mais o seu negócio. No entanto, o que tenta reaver quando reage ao assalto usando uma arma que guardava no balcão é precisamente esse poder que lhe escapa.

Inácio atira em um dos assaltantes que já havia molestado a cliente e queria fazer o mesmo com Sara. O rapaz cai no chão e ele não permite que ninguém lhe preste socorro, nem chame a polícia. O incidente faz eclodir o seu ódio e é também a sua oportunidade de vingança sobre aqueles que vinham ameaçando a pantomima da cordialidade de fachada. Começa, portanto, o banho de sangue que insere o filme na tradição do gênero cinematográfico do horror apensando aspectos de subgêneros conhecidos como o "slasher", "gore" e "giallo".

O que desencadeia a violência e faz com que a personagem passe ao ato é o sadismo de que goza ao se dedicar lentamente a acabar com a vida de um por um daqueles que ali estão e que ele toma como inimigos. Frio, Inácio não tem pressa de matar. Diverte-se ao ver as vítimas desesperadas de medo e se deleita com o terror que inflige a elas antes da morte. O primeiro a morrer é o assaltante que tomou um tiro no peito. A segunda vítima é Verônica, a cliente esnobe, que pede para ficar sozinha no banheiro e também leva um tiro de Inácio ao tentar fugir. O terceiro é o ex-policial Amadeo que, ao agir sozinho tentando demover o dono do restaurante do propósito de continuar matando, é desmascarado em seu intuito de virar um mártir e dar algum sentido a sua vida vazia.

Na sequência, morre o segundo assaltante, não sem antes confessar que Sara é sua mulher e que o assalto era um plano idealizado por ela. $O$ rapaz tem o pescoço cortado com uma faca, a mesma com que Inácio corta o cabelo comprido de Djair que 
assistira à execução ao lado do assaltante. Djair acredita que será o próximo, mas não se acovarda: desfere insultos contra o patrão demonstrando que compreende o que está havendo com esse homem que resolve dar vazão ao seu ódio e sua vontade de matar. Djair o provoca dizendo que o restaurante depende de sua comida e que é isso o que o patrão não suporta: que o sucesso de seu empreendimento dependa da comida de um homossexual, nordestino, de cabelo comprido e sobrancelha fina: "o seu problema, Inácio", grita Djair, "é com meu cu" (O animal cordial, 2018).

Djair não é morto naquele momento. De cabelo cortado, retorna à cozinha e sabe que é deixado para o final como cereja do bolo que o assassino pretende saborear ao ferir. Quem morre em seguida é o advogado, Bruno, que já perdera a esposa e qualquer laivo de dignidade. Está todo urinado e é oferecido pelo patrão a Sara, que deve matá-lo como prova de sua lealdade. O gesto de Inácio, contudo, não passa de uma armadilha. Sara, que teve a posse da arma pela segunda vez, é desmascarada ao tentar atirar no dono do restaurante e perceber que a arma que ele lhe dera era a arma de brinquedo usada no assalto.

Destaco, ainda, para retomar adiante, que Lúcio, o funcionário que havia ido embora e retorna para buscar o celular que havia esquecido é poupado de fazer parte da chacina pela segunda vez porque Sara não permite que ele entre. Lúcio é negro e, acerca disso, ressalto a decisão incomum para roteiros desse gênero cinematográfico, sobretudo no cinema hollywoodiano, em que as personagens negras, além de figurarem como coadjuvantes, são, em geral, as primeiras no descarte da sequência mortífera. Em minha leitura, essa decisão ultrapassa a instância de representação identitária para figurar como um devir-negro, tal como Achille Mbembe (2018) o apresenta, isto é, colocando em questão a própria semântica da palavra "negro" como herança de uma "biblioteca colonial" que constrói o negro como "ficção do outro" (Mbembe, 2018, p. 170).

\section{O ANIMAL CORDIAL}

Com a morte de Verônica, a cliente rica e esnobe que tenta subornar a empregada para que a deixe escapar, Sara avança sobre seu corpo defunto para saqueá-lo. Toma seus brincos, abre sua bolsa e passa seu batom, não antes de brincar com os cílios postiços do cadáver fazendo-os de bigode e de rir da/na cara morta da outra. Mesmo não tendo sido Sara a atirar em Verônica, entendo que seja cúmplice de sua morte, que ambos, Sara e Inácio, sejam coautores das mortes que se passam ali. A atitude de Sara me remete ao matador Araweté' e me faz cotejar suas atitudes pela diferença com que se

\footnotetext{
' Eduardo Viveiros de Castro elucida que a fusão entre o matador e o inimigo é permanente, por isso implica em um devir-outro daquele que mata. $O$ antropólogo destaca a questão da perspectiva que emerge da antropofagia tupi-guarani que passa por essa capacidade de se ver como Outro, isto é, desde um ponto de vista que não seja o seu. Acrescenta ainda que tal concepção do inimigo como aquele com quem se funde ao final da batalha pressupõe a sua humanidade integral, isto é, pressupõe que se estabelece com esse Outro uma relação social no sentido de não considerá-lo uma coisa "(sistema material, corpo anônimo, autômato animal)", nem um igual (a quem não se mata), mas um adversário robusto e diferente de si, com quem se esteja em pé de igualdade para a disputa. Assim, o que acontece, ao cabo, não é a aniquilação escarnecedora desse inimigo, mas a assimilação da própria posição de inimigo que passa a constituir a singularidade do matador (Viveiros de Castro, 2013).
} 
aproximam. O matador da etnia indígena, ao contrário da personagem de Almeida, acredita assimilar o espírito daquele que abateu em uma luta equânime e precisa se afastar das armas e das pessoas de seu convívio, caso contrário, a fúria daquele inimigo, agora fundido a si, pode levá-lo a fazer mal aos seus. Atento para a diferença de perspectiva no modo de re-conhecer o outro, o inimigo. Se para o guerreiro observamos o respeito, a constatação da força e o temor do contágio, para a personagem do filme, interessam as coisas que pertenceram à outra por quem demonstra absoluto desprezo.

Sara se aproxima da morta para zombar e a despoja de seus adereços tomando-os para si. Os adereços eram as armas de Verônica e tanto a distinguiam, quanto submetiam sua rival. Não se trata, pois, de uma batalha entre os atributos de uma e outra singularidade, mas do poder e do status conferidos pelo que se porta ou não, o que se detém a posse ou não: os melhores produtos, os mais caros. Sara saqueia a ostentação da outra e a despreza como adversária, como outro com quem se estabelece alguma relação. Assim, perpetua a sintaxe patriarcal do espólio como forma de dominação e deflagração do poder. Isso faz com que se sinta poderosa ali, naquela microesfera social em que se transforma o restaurante, onde a lei fálica vige em todo o esplendor de sua potência pelas mãos de Inácio, com quem Sara teima em estabelecer uma relação que alterna entre a submissão e a competição.

Desde os primeiros planos, o olhar malicioso da garçonete de baixo para cima sinaliza para algo escondido, uma expectativa, um plano oculto, desejos que talvez se escondam até dela mesma. A princípio, quando o assalto acontece, Sara parece estar apenas reagindo aos acontecimentos, valendo-se das oportunidades para ser valorizada e notada por Inácio. Só depois, com a confissão do assaltante, ela se revela como mandante do saque fracassado. Sara é maledicente com os colegas, delata o ex-policial que sugere chamar a polícia, trai seu suposto comparsa e amante deixando que seja morto por Inácio e também trai Inácio as duas vezes que tem a posse da arma: a primeira vez ordenando a ele que tire a roupa e a segunda quando, constrangida a provar-lhe fidelidade, volta-se com a arma para matá-lo.

A que $(\mathrm{m})$ Sara é fiel? O que ela quer? Onde pretende chegar? Afinal, o que quer a mulher?, é a pergunta freudiana que salta da boca de Djair convocando Sara a encarar e situar seu gozo. Uma libido à flor da pele fica cada vez mais perceptível em Sara conforme o roteiro se desenvolve. Desde o início do filme, quando Inácio, distraído, esbarra em seu braço detrás do balcão onde trabalham juntos, a reação da funcionária é focalizada. Ela o deseja sexualmente e também o detesta. Des-equilibra-se nessa ambivalência. $A$ cena de sexo emula, pois, o ápice do desembaraço desse apetite sexual retesado que só eclode dando vazão a toda violência que o sustém, daí o orgasmo estratosférico de seu corpo convulsionando sobre o corpo de Inácio na cena em que ela determina os termos e a hora. Inácio estendido no chão, mais espectador que parceiro daquele gozo em que ela se contorce plena com seu corpo banhado de sangue sobre um falo que toma para si com o arrojo de quem assume as rédeas de sua cavalgada.

Sara goza e isso libera em si uma fome animal. Vai até a cozinha e devora uma carne com osso, rosna para o cliente playboy e ouve, mais uma vez, os questionamentos de 
Djair indagando sobre o que ela realmente quer e para onde está indo com tudo o que faz. Djair a convoca para fora do horror sanguinário convidando-a a parar de ceder ao impulso sádico e pedindo que solte as amarras de seus punhos. As perguntas evocam um silêncio em Sara, batem em algum lugar e retornam. Tanto é assim que Sara se vai, mas adiante, noutra oportunidade, decide soltar Djair.

Tudo isso a respeito da personagem concorre para dizer como o título do filme promove uma rasura do homem cordial de Holanda (1995). Se Inácio encarna essa estrutura do declínio humanista, o que assistimos é o instante da derrocada do homem, sua derrota para o animal que no lapso do movimento desastrado, na falha do ato, se solta da coleira e não sabe exatamente aonde ir. É como fica Sara, ali, ao pé do dono/ senhor, sem saber se o destrói, se foge, ou se desiste da fuga. Ela que assentira com o jogo ao qual fora lançada desde que, um dia, se entendeu por mulher e decidiu virar o tabuleiro, mas não sabe se recolhe as peças, se levanta da mesa, ou se continua a jogar. A meu ver, é essa estrutura da dialética hegeliana em que não há espaço para o outro que desponta inteiro e vivo na diferença. É essa dialética do aniquilamento que fica exposta e esgarçada no filme através da (não-)relação entre o homem e a mulher, protagonizados por Inácio e Sara.

Hélène Cixous (1995), ao dizer do lugar da mulher como construção discursiva que oferece a sustentação à primazia do falo explica que, conforme essa lógica, a mulher é a "delícia-perigo" que precisa existir como instância depositária de todo mistério, mal e fascínio e da qual é preciso preservar a distância adequada para manter incólume a ordem, a moral e a razão. Nesse sentido, a desumanização da mulher guarda reciprocidade com os métodos de constituição do negro como "sujeito racial" ${ }^{2}$, que é outro efeito da primazia fálica. Desde que aprende a falar, portanto desde sua constituição como sujeito, a mulher, afirma Cixous (1995), assimila que seu nome é África, que é "negro" (Cixous, 1995, p. 20). Isso implica que há uma identificação da mulher com todo o espectro de sentidos consignados por essa terrível construção discursiva que institui, subjuga e aparta o negro do mundo, sobretudo dele mesmo. Assim, a mulher é o continente negro e perigoso porque o negro é perigoso, no negro nada se vê. O horror ao escuro foi interiorizado e separou a mulher de si mesma, do que ela quer.

O filme, a meu ver, é o processo pelo qual essa mulher se despe, encarna a animalidade e se destaca (mas não completamente) do humano (tal como é habitualmente concebido: falo-hetero-eurocentricamente) para estar no plano horizontal com os outros mundos. Desse lugar animalesco, que é o da própria diferença, emerge uma cordialidade

\footnotetext{
${ }^{2}$ Acerca do processo histórico de instituição da raça Achille Mbembe argumenta tratar-se de uma forma de representação primária calcada em preconceitos que, no momento gregário do pensamento ocidental, reduziu os mundos exteriores e complexos que não se podia aceder, nem entender a simplificações que os inferiorizava. Mbembe explica que, nesse sentido, o negro é constantemente produzido, o que gera um corpo-coisa, isto é "um corpo inteiramente exposto à vontade de um senhor" (Mbembe, 2018, p. 42). Nesse sentido, Mbembe perora que a razão negra consiste em um "sistema pretensamente erudito de narrativas e discursos" que consignam uma origem africana falada em seu nome. Tratam-se tanto de discursos quanto de práticas que inventam o negro como "sujeito racial e exterioridade selvagem, passível de desqualificação moral e de instrumentalização prática" (Mbembe, 2018, pp. 60-61). Assim, a raça teria o papel de engendrar um simulacro, uma máscara que escamoteie o rosto humano a fim de que não se reconheça naquele outro cuja face devolve impertinente uma imagem daquele que o vê. É preciso, então, cobri-lo com o véu da raça para que não seja estabelecida uma relação, para que o outro não aponte a deformidade do eu.
} 
que já não é mera pantomima para melhor controlar e dominar o outro, mas uma cordialidade que nasce da alteridade. Assim, pensar esse aspecto original da cordialidade passa necessariamente pela rasura e reescrita de dois enunciados: 1. "a mulher é negro" e 2. "a mulher é bissexual". Ambos os procedimentos, digamos assim, começam com a pergunta reiterada por Djair, que não cessa de se inscrever nos planos do filme de Almeida (2018), nos ouvidos de Sara, perfurando esses sintagmas.

Penso nessas re-escritas como formas de despojamento da máscara humana: ao deixar cair as máscaras do cinismo, que é o que acontece gradualmente no restaurante conforme Sara e Inácio se despem e deixam cair também os pudores, as mesuras, os interditos. Ao reescrever as frases borrando a sintaxe com o roteiro que preserva o negro e o homossexual, o filme enceta devires.

\section{DeVIres LúCIO E DJAIR}

Lúcio, Sara e Djair são as personagens que terminam vivas. É importante retomar a personagem de Lúcio para lembrar que fora poupado da morte por duas vezes: a primeira quando Sara aceita ficar até mais tarde no restaurante e o dispensa para ir embora; e a segunda quando ele volta, tarde da noite, para buscar o celular que diz ter esquecido e Sara convence Inácio a deixá-lo de fora da chacina impedindo-o de entrar. Entendo que essa é a cordialidade animal que só acontece na diferença. Ao olhar para Lúcio, Sara recebe em retorno uma imagem de si mesma com que não se identifica. Ela sustenta essa diferença vendo-se obrigada a reconhecer esse outro e a tomar uma atitude em relação a ele. Sua atitude é a de preservá-lo do horror, mantê-lo fora dos limites daquela violência. Eis a reescrita promovida pelo roteiro que desarticula a construção: "a mulher é negro" (O animal cordial, 2018). A mulher não é negro na medida em que lê, por baixo da máscara do racismo, uma imagem de dessemelhança a si. É capaz de percebê-lo como outro que não faz parte daquela carnificina e isso tem como efeito assentir com o fato de que esse outro, tendo uma perspectiva, Ihe devolva uma imagem distinta da que tem sobre si mesma. Que ela não saia de lá com ele faz com que esteja implicada na matança até o tutano, mas deixá-lo de fora sinaliza uma abertura à perspectiva do outro. É nesse sentido que entendo que a personagem de Lúcio aponta para um devir, o devir-negro de Sara.

Se, por um lado, Lúcio está fora do restaurante, Djair está de saída. Porém, não sai antes de recolher seu cabelo cortado e convidar Sara para se levantar e ir também. Ela fica porque tem trabalho a concluir. Sara precisa matar e esquartejar o homem cordial. Sara não sai porque está embebida de sangue, não apenas porque se banqueteou, com o homem cordial, de toda violência que decorre da supremacia fálica, mas porque é também, ela mesma, feita de cacos da imagem estilhaçada desse homem. Sara fica viva, mas não sai porque não pode. Não porque necessite de uma vingança, não porque o esquartejamento que precisa concluir a deixará livre para se refugiar atrás de um álibi qualquer, mas porque faz parte dessa velha ordem que escorou e agora ajuda a ruir. Sabe que a derrocada desse homem cordial é o fim também de uma mulher cordata e submissa à cordialidade. 
O animal cordial, tal como leio, é a própria transição e precisa se apropriar dessa condição transitória para vislumbrar devires. Ele/ela surge do confronto, do enfrentamento da ordem patriarcal/patronal e sabe que não pode, não deve liberar o seu oposto simétrico, cujo efeito seria o de ratificar aquela mesma lógica, ainda que por outro viés. Sara não sai do restaurante porque, no íntimo, sabe, desde sua condição de animal cordial, que "o homem é aquele que se conhece, que se reconhece como tal, conhece a si e re-conhece a si em seus semelhantes, sua espécie, aqueles que são, a sua imagem e semelhança, seus espelhos" (Nodari, 2017, p. 26). No entanto, ao contrário desse reconhecimento que não passa de uma projeção de si no outro, Alexandre Nodari (2017) afirma que a literatura, como as artes, em geral, evocam essa possibilidade de fabulação, operando como

espelhos deformantes [que] colocam no primeiro plano o diferimento (ou refração) das imagens do humano, postulando o estranhamento de si (um "outrar-se") como forma privilegiada de conhecimento (e até mesmo de si: a melhor perspectiva de si é a do outro, para fazer uso de um mote central de Eduardo Viveiros de Castro). (Nodari, 2017, p. 26)

Esse outro a que nos remete o antropólogo, é o outro diante do qual Jacques Derrida (2011) afirma que é preciso estar desnudo para que começar a pensar fosse possível. Desnudar-se diante do outro que não me reconhece como vivente nomeador, que não responde a mim com a língua com que tenho a pretensão de nomeá-lo, seria oferecer a ele uma perspectiva que devolveria a mim uma impressão a meu respeito diferente da que posso almejar diante de outro homem. A palavra animal "é uma denominação que os homens instituíram, um nome que eles se deram o direito e a autoridade de dar a outro vivente" (Derrida, 2011, p. 48). Contudo, o filósofo não despreza a ruptura, não pretende ignorar a distância abismal que dista o homem do animal. O que ele propõe com referência a essa margem é espessá-la, dobrá-la, complicá-la, multiplicá-la e, com isso, mostrar a potência de um pensamento mais liberto e menos obtuso, menos estanque na nomeação narcísica propiciada dêitico sui-referencial: "eu". Derrida (2011) acusa a história do pensamento ocidental de ser uma autobiografia contada pelo homem de si para si na pretensão de se apresentar no presente e excluindo a possibilidade de ser visto, sobretudo nu, por uma outra espécie, isto é, da acuidade de se perceber sob outro ponto de vista. Dito isso, retomo com a personagem Sara para dizer que ela se despe de sua humanidade diante de quem quer que a veja e permite que seu corpo seja visto por outras perspectivas, tal como na cena em que vorazmente se alimenta na cozinha diante de todos.

Dessa forma, penso que quem ela liberta, portanto, é o devir-Djair, ou, no sentido apropriado por Cixous (1995), a bissexualidade, como lugar de acolhimento e coexistência da diferença, não como neutralidade3. Liberta-se, portanto, o "queer", o trans, a

\footnotetext{
${ }^{3}$ Cixous (1995) estabelece duas acepções quanto à bissexualidade: de um lado, ela designaria a fantasia de um ser total que substituiria o medo da castração e ocultaria a diferença sexual na medida em que remete à marca de uma separação mítica. Nessa acepção, o bissexual estaria mais para um assexuado que se compõe de duas metades e não de dois gêneros. $A$
} 
mulher-homem, o homem-mulher, a própria liberdade para olhar de fora e para fora, isto é, de outra perspectiva que extrapole as estruturas sexuais e de pensamento. Djair em nenhum momento compactua com o horror do que acontece ali. O que faz é conversar com as personagens encarceradas para que se acalmem, mantenham alguma serenidade e às vezes até para tentar ajudá-las a transcender o horror. É o que faz por Sara ao insistir com as perguntas, ou pelo homem molhado de medo a quem "prepara" uma receita de família como quem oferece um alento, algum conforto.

Djair, aliás, já havia pedido demissão do restaurante há um mês, faz tempo que havia se desligado do lugar, que não fazia parte da equipe. Seu prazer está em outro lugar: nas plantas que gosta de regar, na dança, no namorado e não faz laço com o ambiente doentio e infernal do restaurante. Seu desejo no corpo, em seu cabelo que recolhe do chão e pelo qual precisa elaborar o luto dessa decepção. Trata-se de uma perda que, apesar de violenta, também nos diz da precariedade da resistência do homem cordial em tentar cortar o movimento que o consome. O cabelo de Djair é a impertinência da vida em sua forma imperecível e imputrescível e torna a crescer porque sobreviveu àquela noite, mas continuaria a crescer de qualquer forma porque os cabelos insistem para além dos cadáveres. É uma imagem potente essa inscrita no cabelo, no corpo que desafia a morte e do que, mesmo na morte, é vida teimando em fazer corpo.

Embora o filme não termine nesse ponto, com a digníssima saída de cena de Djair, e nos devolva ao deslumbrante corpo nu e ensanguentado de Sara determinada a lidar com os despojos do homem cordial, é Djair rasurando a bissexualidade fantasma e expondo como o toque e delicadeza têm vez em seu corpo, paralelamente a Lúcio desafiando a semântica colonial do negro, que apontam para uma rota de fuga e sinalizam para $o$ aberto. Essas personagens remetem a possibilidades mais amplas de mundos para fora da clausura do restaurante que, apesar de todo sangue, todo limo ofertado pelo filme de Gabriela, nos permitem sonhar com trocas, nomeações, delegações, mutualidades e reciprocidades que envolvem "Todo-Mundo", para lembrar essa expressão vigorosa usada por Mbembe (2018).

\section{REFERÊNCIAS}

Almeida, G. A. [Realizadora] (2018). O animal cordial [Filme]. Brasil: California Filmes.

Cixous, H. (1995). La joven nacida. In H. Cixous (Ed.), La risa de la Medusa: ensayos sobre la escritura (pp. 13-107). Barcelona: Anthropos; Madrid: Comunidad de Madrid. Consejería de Educación. Direeción General de la Mujel'; San Juan: Universidad de Puerto Rico.

Derrida, J. (2011). O animal que logo sou. São Paulo: Editora Unesp.

Holanda, S. B. (1995). Raízes do Brasil. São Paulo: Companhia das Letras.

outra bissexualidade de que fala a filósofa é, por outro lado, a que não encerra o sujeito no que entende ser "o teatro da representação falocêntrica", trata-se da localização em si da presença dos dois sexos a se manifestar conforme a singularidade de cada um, uma. A consequência dessa outorga, diz-nos Cixous, é a multiplicação dos efeitos de inscrição do desejo em todas as partes dos corpos, do eu e do outro. 
Mbembe, A. (2018). Crítica da Razão Negra. São Paulo: n-1 edições.

Nodari, A. (2017). Filozoofia. Revista Canguru, 2, 21-27. Retirado de https://issuu.com/revista_canguru/docs/ canguru_O2

Viveiros de Castro, E. (2013). A imanência do inimigo. In E. Viveiros de Castro (Ed.), A inconstância da alma selvagem e outros ensaios de antropologia (pp. 267-294). São Paulo: Cosac Naify.

\section{NotA BIOGRÁFICA}

Fernanda Ribeiro Marra (Universidade de Brasília - UnB) é doutoranda em Teoria Literária pelo Programa de Pós-Graduação da Universidade de Brasília, com pesquisa sobre a obra da poeta argentina Alejandra Pizarnik. Manteve, entre 2008 e 2015, o blogue Marés e Ressacas, onde divulgou sua produção poética, que agora será reunida no livro taipografia, pela martelo casa editorial. Além disso, a autora tem trabalhos de crítica publicados em revistas acadêmicas brasileiras como Landa, Entrelaces e Versalete.

Email: dizamarra@gmail.com

Morada: Universidade de Brasília, Campus Universitário Darcy Ribeiro, Brasília-DF | CEP 70910-900, Brasil

* Submetido: 06-09-2018

* Aceite: 02-01-2019 